\title{
Effective school-based preventive interventions for alcohol use in Africa: a systematic review
}

\author{
Sachi Tomokawa ${ }^{1}$, Kimihiro Miyake ${ }^{1}$, Takeshi Akiyama ${ }^{2}$, Yuka Makino ${ }^{3}$, Akihiro Nishio ${ }^{4}$, \\ Jun Kobayashi ${ }^{5}$, Masamine Jimba ${ }^{6}$, Irene Ayi ${ }^{7}$, Sammy M Njenga ${ }^{8}$, Takashi Asakura ${ }^{9}$
}

1. Department of sports and sciences, Faculty of Education, Shinshu University, 6-Ro Nishi Nagano, Nagano City, Nagano 380-8544, Japan.

2. Department of Health Science, Nagano College of Nursing, 1694 Akaho, Komagane city, Nagano, 399-4117, Japan.

3. Japanese Consortium for Global school Health and Research, 207 Uehara, Nishihara, Okinawa 903-0215, Japan.

4. Health Administration Center, Gifu University, 1-1 Yanagido, Gifu City 501-1193, Japan.

5. Department of Global Health, University of the Ryukyus, 207 Uehara, Nishihara, Okinawa 903-0215, Japan.

6. Department of Community and Global Health, Graduate School of Medicine, The University of Tokyo, 7-3-1 Hongo, Bunkyo-ku, Tokyo 113-0033, Japan.

7. Department of Parasitology, Noguchi Memorial Institute for Medical Research, College of Health Sciences, University of Ghana, P. O. Box LG 581, Legon, Accra, Ghana.

8. Kenya Medical Research Institute, P.O. Box 5484000200 Off Mbagathi Road, Nairobi, Kenya.

9. Faculty of Education, Tokyo Gakugei University, 4-1-1, Nukuikita, Koganei-city, Tokyo , 184-8501, Japan.

\begin{abstract}
Background: Despite recognition of the risks of alcohol use and importance of prevention from an early age, the effectiveness of school-based interventions in Africa has not been clarified.

Objective: We aimed to identify effective school-based alcohol use prevention interventions in Africa.

Methods: We searched eight databases for peer-reviewed articles published until February 3, 2019 that reported on randomized controlled trials, cluster randomized controlled trials, controlled clinical trials, pre-post quasi-experimental studies, cohort studies, and case-control studies. The full-texts of relevant studies were searched.

Results: Four of 2797 papers met our eligibility criteria. All reported interventions targeted secondary school students in South Africa and were incorporated in the school curriculum. The interventions comprised multi-component activities with participatory and peer educational methods, and applied modified programs originally developed in the US. However, intervention effects were inconsistent among studies, although the interventions tended to have a positive effect on non-drinkers at baseline, with stronger effects in girls.

Conclusion: interventions had positive effects on students that were non-drinkers at baseline, especially girls. Although we could not find robust evidence that school-based interventions changed attitudes, frequency/quantity of drinking, and intentions to use alcohol, one intervention showed an increase in students' alcohol refusal self-efficacy.
\end{abstract}

Keywords: School-based preventive interventions, alcohol use, Africa, systematic review.

DOI: https://dx.doi.org/10.4314/ahs.v20i3.45

Cite as: Tomokawa S, Miyake K, Akiyama T, Makino Y, Nishio A, Kobayashi J, et al. Effective school-based preventive interventions for alcohol use in Africa: a systematic review. Afri Health Sci. 2020;20(3): 1397-1406. bttps:/ / dx.doi.org/10.4314/ ahs.v20i3.45

\section{Corresponding author:}

Tomokawa Sachi,

Department of sports and sciences,

Faculty of Education, Shinshu University,

6-Ro Nishi Nagano, Nagano City, Nagano

380-8544, Japan.

Tel : +81-26-238-4167, FAX :+81-26-234-5540

Email: sachitjp@shinshu-u.ac.jp

\section{Introduction}

The World Health Organization (WHO) reported that the harmful use of alcohol is a component cause of more than 200 disease and injury conditions in individuals ${ }^{1}$. Globally, about 3.3 million deaths in 2012 (5.9\% of all deaths) were attributable to alcohol consumption. The alcohol-attributable burden of disease is increasing in Africa, with $6.4 \%$ of deaths attributed to harmful use of alcohol in 2012 compared with $2.1 \%$ in 2000 . Alco-

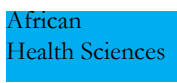

(C) 2020 Tomokawa S et al. Licensee African Health Sciences. This is an Open Access article distributed under the terms of the Creative commons Attribution License (https://creativecommons.org/licenses/BY/4.0), which permits unrestricted use, distribution, and reproduction in any medium, provided the original work is properly cited. 
hol consumption has a major impact on the burden of disease and mortality in Africa ${ }^{2,3}$.

Early initiation of alcohol use is a predictor of impaired health status because it is associated with increased risks for alcohol dependence and abuse in later life ${ }^{4-8}$, alcohol-related motor vehicle crashes ${ }^{9,10}$, and other unintentional injuries ${ }^{11,12}$. In addition, alcohol use results in an increased risk for non-communicable diseases (NCDs), meaning that preventive interventions in childhood are more important to reduce health risks than later interventions among adults. The critical role of schools in providing a foundation to ensure healthy growth in children and adolescents was emphasized by the Global Strategy for Women's, Children's, and Adolescents' Health, and the WHO Global Action Plan for the Prevention and Control of NCDs 2013-202013,14.

Previous systematic reviews confirmed the effectiveness of school-based interventions in preventing alcohol use ${ }^{15-19}$. One review reported that certain generic psychosocial and developmental prevention programs may be effective ${ }^{16}$. Another review indicated schoolbased preventive interventions reduced the frequency of drinking, and a program that combined substance abuse was effective ${ }^{19}$. It has also been reported that interactive programs to prevent alcohol use that actively involved students as peer leaders were effective ${ }^{15}$.

However, few studies on school-based interventions to prevent alcohol use have been conducted in Africa, and effective school-based approaches adapted to the African context have not been clarified. Therefore, we aimed to identify effective school-based alcohol use prevention interventions in Africa.a search for relevant papers published until February 3, 2019 (with no limitation of publication year) using eight databases: $\mathrm{Pu}-$ bMed, Web of Science, SCOPUS, ERIC, PsycINFO, CINAHL, Popline, and the Cochrane Central Register of Controlled Trials. We also searched for eligible papers in the Cochrane Library and four relevant academic journals: Journal of School Health, Health Education Research, Health Promotion International, and Tropical Medicine \& International Health. We defined keywords as search terms and used these terms for searching all databases, although the formula for each database differed depending on the database syntax. For example, the formula used in PubMed was: school* AND (child* OR adolescen* OR student* OR pupil*) AND ("Africa" OR "Algeria" OR "Angola" OR "Benin" OR "Botswana" OR "Burkina Faso" OR "Burundi” OR "Cabo
Verde" OR "Cameroon" OR "Central African Republic" OR "Chad" OR "Comoros" OR "Congo" OR "Republic of the Congo" OR "Democratic Republic of the Cote d'Ivoire" OR "Djibouti" OR "Egypt" OR "Equatorial Guinea" OR "Eritrea" OR "Ethiopia" OR "Gabon" OR "Gambia" OR "Ghana" OR "Guinea" OR "Guinea-Bissau" OR "Kenya" OR "Lesotho" OR "Liberia" OR "Libya" OR "Madagascar" OR "Malawi" OR "Mali" OR "Mauritania" OR "Mauritius" OR "Morocco" OR "Mozambique" OR "Namibia" OR "Niger" OR "Nigeria" OR "Rwanda" OR "Sao Tome and Principe" OR "Senegal” OR "Seychelles" OR "Sierra Leone" OR "Somalia" OR "South Africa" OR "South Sudan" OR "Sudan" OR "Swaziland" OR "Tanzania" OR "Togo" OR “Tunisia" OR "Uganda" OR "Zambia” OR "Zimbabwe") AND (alcohol*).

\section{Inclusion criteria}

\section{Type of study}

We identified randomized controlled trials (RCTs) including cluster RCTs (C-RCTs), and non-randomized controlled studies including controlled clinical trials (CCTs) and pre-post quasi-experimental studies, cohort studies, and case-control studies. We selected relevant papers that were peer-reviewed.

\section{Types of participants and study area (population)}

Target participants were children and young people aged 4-18 years attending school or college. The study area was limited to Africa.

\section{Types of interventions}

We targeted school-based interventions. In this paper, we used "school-based" to indicate schools as the setting in which activities were conducted.

\section{Exclusion criteria}

Studies were excluded if the interventions did not meet all of the above inclusion criteria. Language was not an exclusion criterion. We excluded hospital-, family-, and community-based studies.

\section{Types of Outcome measures}

Outcome measures were direct self-reported or objective measures of children's alcohol use, alcohol refusal self-efficacy, attitudes about alcohol, and perceived peer drinking.

\section{Data collection and analysis}

Two independent reviewers completed broad screening of the titles and abstracts of all identified papers. Next, 
those reviewers independently assessed the full-texts of all potentially relevant articles that passed the initial title/abstract screening. Differences in opinion arising at either screening level were resolved through discussion. A flow chart of the review process is presented in Figure 1.

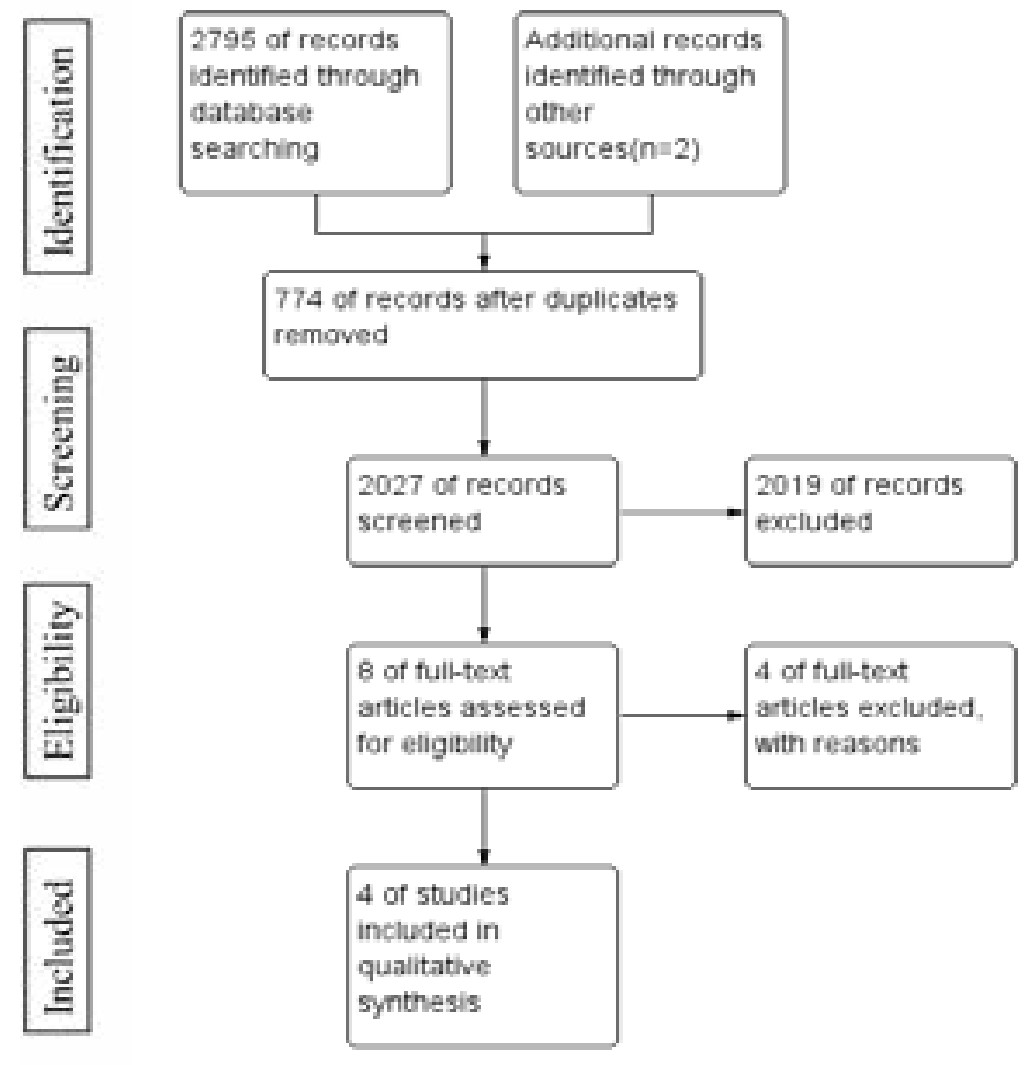

Figure1. Flow chart of the review

\section{Assessment of risk of bias in included studies}

For each study, tTwo reviewers independently assessed the risk of bias for each study using the Cochrane Col- laboration tool for RCTs and C-RCTs ${ }^{22,23}$ (Figure 2). The risk of bias in non-RCTs was assessed with the ROBINS-I tool ${ }^{24}$ (Figure 3).

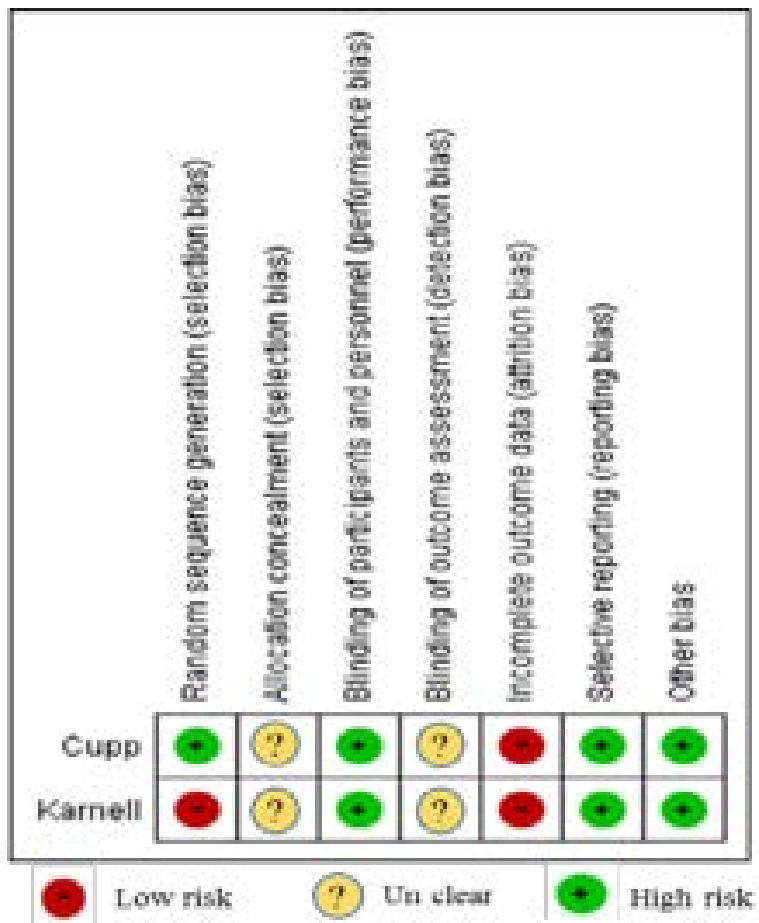

Figure2. Risk of bias summary for RCT study 


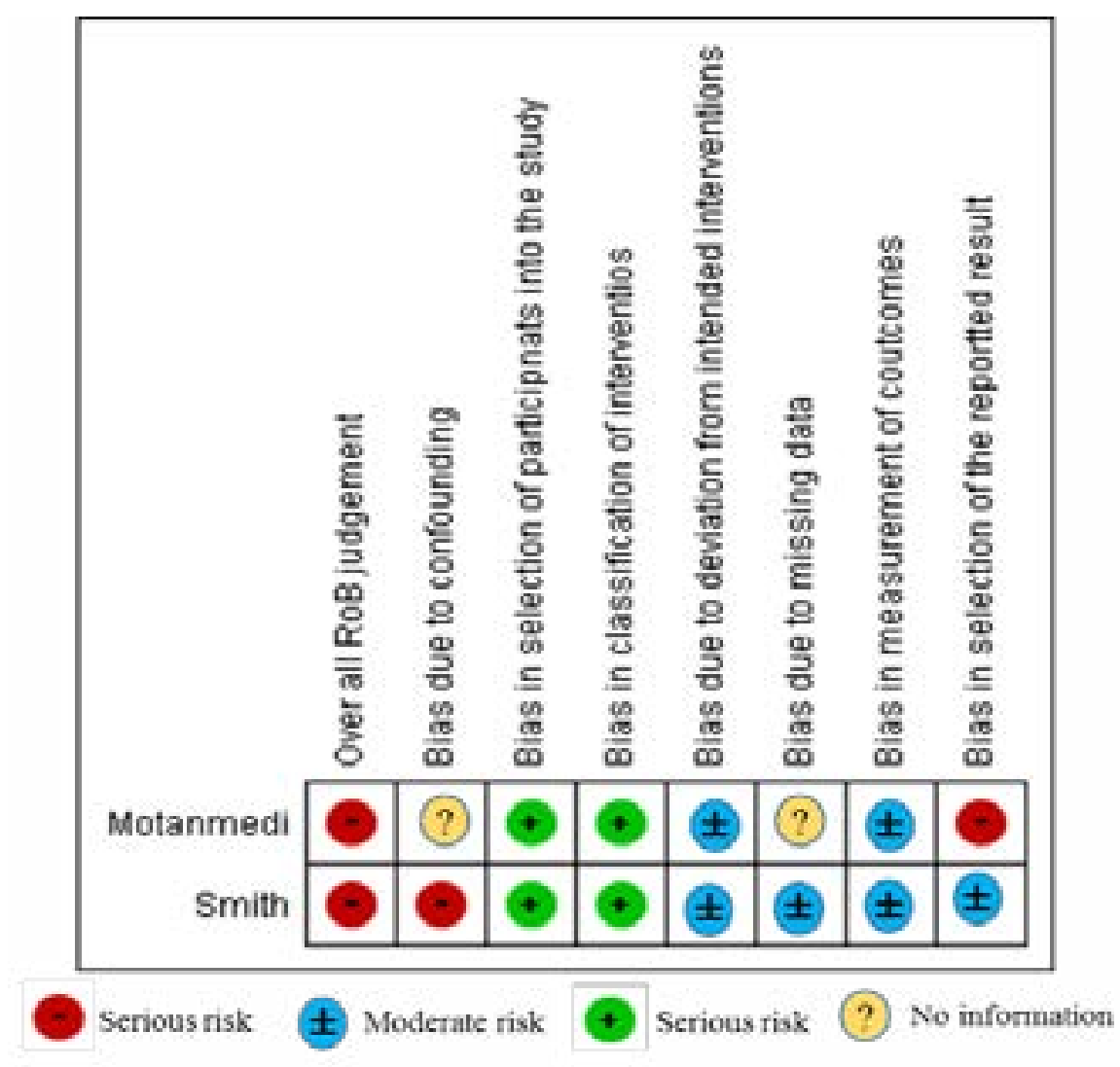

\section{Figure3. Risk of bias summary for non-RCT study}

\section{Results}

\section{Characteristics of included studies}

In total, Four of 2797 retrieved papers met the eligibility criteria ${ }^{25-28}$. Table 1 presents an outline of these four papers. Two studies were C-RCTs ${ }^{27,28}$ and two were CCTs 25,26. All studies were conducted in South Africa and targeted secondary school students. Two studies used a modified "HealthWise" program, which was originally developed in the US. HealthWise is a school-based prevention program for reducing substance use and risky sexual behavior that targets youths' leisure time (positive use of free time) and developing their social-emotional skills ${ }^{27,28}$. This program comprised 12 lessons in grade 8 and six lessons in grade 9. Lessons were provided in English and Afrikaans by a manualized curriculum that fit within the existing life orientation curriculum. The remaining two studies used another modified pro- gram ("Our Times, Our Choices"), which was also developed in the US ${ }^{25,26}$. Our Times, Our Choices aimed to prevent alcohol use and reduce HIV-related risky sexual behaviors. This program applied a participatory approach involving student peer leaders. Peer leaders received training on the program alongside the teachers involved, and helped to lead group discussions. The peer leaders assisted with interactive activities and encouraged others to participate in the lessons. A series of monologues by fictional teenagers delivered via $\mathrm{CD}$ and audio vignettes were used as the basis for class discussion and group assignments. All four interventions were conducted with mixed methods: components on alcohol use prevention and reduction of risky sexual activity in HealthWise, and alcohol use prevention and HIV/AIDS prevention in Our Times, Our Choices. Moreover, all interventions were incorporated in existing life skills education classes. 


\begin{tabular}{|c|c|c|c|c|c|c|}
\hline Author (year) & Country (area) & Study design & Target and control populations & Intervention & Outcomes & Main findings \\
\hline $\begin{array}{l}\text { Karnell } \\
(2006)\end{array}$ & $\begin{array}{l}\text { South Africa } \\
\text { (Pietermaritzburg) }\end{array}$ & C-RCT & $\begin{array}{l}\text { Intervention: } 325 \text { students } \\
\text { in } 9^{\text {th }} \text { grade } \\
\text { Control: } \\
336 \text { students in } 9^{\text {th }} \text { grade }\end{array}$ & $\begin{array}{l}\text { The program used was a modified version of } \\
\text { a program originally developed in the USA. The } \\
\text { program comprised } 10 \text { units of } 30 \text { minutes and duration of the } \\
\text { intervention was about eight weeks. Teachers of the } \\
\text { schools involved in the study received } 2 \text { days of training. A } \\
\text { series of monologues of four fictional teenagers was used as a } \\
\text { basis for discussions and assignments. Four peer leaders in } \\
\text { each class who had received } 2 \text { day training were responsible } \\
\text { for the discussion. About half of the curriculum focused on } \\
\text { alcohol-related issues and the other half concerned HIV- } \\
\text { related issues. }\end{array}$ & $\begin{array}{l}\text { (1) Experience of alcohol use } \\
\text { (2) Frequency of alcohol use } \\
\text { (3) Quantity of alcohol use } \\
\text { (4) Four-item alcohol problem scale } \\
\text { (5) Extent of positive attitudes toward } \\
\text { alcohol use } \\
\text { (6) Respondents' perceived abilities to } \\
\text { refuse alcohol }\end{array}$ & $\begin{array}{l}\text { No significant direct intervention effects were found } \\
\text { on any of the alcohol--related outcomes (alcohol- } \\
\text { related behavioral, frequency and quantity of alcohol } \\
\text { use, and alcohol-related problems). Similarly, no } \\
\text { intervention effects were found on any of the } \\
\text { mediating alcohol-related variables, including } \\
\text { alcohol-related self-efficacy and attitudes about } \\
\text { alcohol. However, students in the intervention group } \\
\text { who had not had sex at the time of the pretest were } \\
\text { less likely to drink or indicated that their partners } \\
\text { were not drinking before or during the last time they } \\
\text { had sex. }\end{array}$ \\
\hline $\begin{array}{l}\text { Smith } \\
\text { (2008) }\end{array}$ & $\begin{array}{l}\text { South Africa } \\
\text { (Mitchell's Plain) }\end{array}$ & CCT & $\begin{array}{l}\text { Intervention: } 901 \text { students } \\
\text { in } 9^{\text {th }} \text { grade (Girls } 52 \% \text { ) } \\
\\
\text { Control: } \\
1,275 \text { students in } 8^{\text {th }} \text { grade (Girls } \\
51 \% \text { ) }\end{array}$ & $\begin{array}{l}\text { The program used was a modified version of a program } \\
\text { originally developed in the USA. The program consisted of } 12 \\
\text { lessons in } \text { th grade, followed by six booster lessons } \text { in } 9^{\text {th }} \text { grade. Each lesson required two to three class periods. } \\
\text { Lesson topics covered social-emotional skills programs (e.g., } \\
\text { anxiety and anger management, decision making, self- } \\
\text { awareness) and also targeted the positive use of free time. } \\
\text { These lessons were complemented by specific lessons on } \\
\text { attitudes, knowledge, and skills surrounding substance use and } \\
\text { sexual risk (e.g., relationships and sexual behavior, condom } \\
\text { use, realities and myths of drug use). The curriculum was } \\
\text { provided in either English or Afrikaans. }\end{array}$ & $\begin{array}{l}\text { (1) Lifetime alcohol use } \\
\text { (2) Alcohol use in the past } 4 \text { weeks } \\
\text { (3) Intensity of alcohol use in the past } \\
4 \text { weeks (Heavy use: four or more } \\
\text { drinks/week; light use: 1-3 } \\
\text { drinks/week) }\end{array}$ & $\begin{array}{l}\text { No difference between the control and intervention } \\
\text { groups was found in the initiation of alcohol use. } \\
\text { Alcohol use in the past month among all participants } \\
\text { showed positive effects in both sexes, but the effect } \\
\text { was especially strong for girls. Among the } \\
\text { subsample of baseline non-drinkers, girls in the } \\
\text { intervention group showed a positive effect on past } \\
\text { month drinking, but there was no effect for boys. } \\
\text { Among all participants, the control group had a } \\
\text { significantly larger increase in rates of heavy past- } \\
\text { month alcohol use. Among the subsample who had } \\
\text { not tried alcohol before the study, the main effect } \\
\text { indicated a positive effect in intervention group on } \\
\text { past-month heavy drinking; the sex interaction was } \\
\text { not significant. The control group had steeper } \\
\text { increases in recent (OR 1.4, 95\% CI 1.1-1.8) and } \\
\text { heavy use of alcohol (OR 1.6, } 95 \% \text { CI 1.2-2.2). }\end{array}$ \\
\hline $\begin{array}{l}\text { Cupp } \\
\text { (2008) }\end{array}$ & $\begin{array}{l}\text { South Africa } \\
\text { (Pietermaritzburg) }\end{array}$ & C-RCT & $\begin{array}{l}\text { Total: } \\
1095 \text { students in } \\
9^{\text {th }} \text { grade (Girls 54\%). } \\
\text { Intervention: students from four } \\
\text { schools. } \\
\text { Control: students from four } \\
\text { schools. }\end{array}$ & $\begin{array}{l}\text { The program used was a modified version of a program } \\
\text { originally developed in the USA. The program comprised } 15 \\
\text { units } 30-40 \text { min), and was delivered over about eight weeks. } \\
\text { About } 40 \% \text { of the curriculum focused on alcohol-related } \\
\text { issues, and the remainder on reducing risky sexual } \\
\text { activity. Teachers in intervention schools received } 3 \text { days of } \\
\text { the training and teachers in the controls received single day of } \\
\text { training. The intervention drew on peer assistants who } \\
\text { received } 2 \text { day training. Peer assistants helped lead group } \\
\text { discussions, assisted with interactive activities, and } \\
\text { encouraged others to participate in the lessons. The } \\
\text { intervention featured a series of monologues by four fictional } \\
\text { township teenagers delivered via CD. Ten of the } 15 \text { lessons } \\
\text { featured these audio vignettes, which often served as the basis } \\
\text { of class discussion and group assignments. }\end{array}$ & $\begin{array}{l}\text { (1) Experience of alcohol use } \\
\text { (2) Attitude toward alcohol use } \\
\text { (3) Alcohol refusal self-efficacy }\end{array}$ & $\begin{array}{l}\text { The intervention groups were less likely to indicate } \\
\text { intention to use alcohol with sex during the next } 3 \\
\text { months ( }<<0.05 \text { ). The intervention groups showed a a } \\
\text { greater increase in their ability to refuse alcohol and } \\
\text { alcohol refusal self-efficacy ( }<0.01 \text { and } p<0.05 \text {, } \\
\text { respectively). There were no intervention effects } \\
\text { with regard to attitudes and intention to use alcohol. } \\
\text { Alcohol-related behavioral outcomes showed no } \\
\text { significant intervention effects for ever using } \\
\text { alcohol. The effects of the intervention on alcohol } \\
\text { refusal self- efficacy were greater in boys than in } \\
\text { girls, and effects on intention to use alcohol with sex } \\
\text { were greater in girls. }\end{array}$ \\
\hline Motanmedi (2016) & $\begin{array}{l}\text { South Africa } \\
\text { (Mitchell's Plain) }\end{array}$ & CCT & $\begin{array}{l}5610 \text { students who had baseline } \\
\text { data } \\
(63 \% \text { in control and } 37 \% \text { in } \\
\text { intervention) }\end{array}$ & $\begin{array}{l}\text { The program used was a modified version of a program } \\
\text { originally developed in the USA. The program aimed to } \\
\text { reduce substance use and risky sexual behavior. It comprised } \\
12 \text { lessons in } 8^{\text {th }} \text { grade and six lessons in } 9^{\text {th }} \text { grade; lessons } \\
\text { were provided in English or Afrikaans by a manualized } \\
\text { curriculum that fit with existing life orientation curriculum. }\end{array}$ & $\begin{array}{l}\text { (1) Initiation of alcohol use (rate } \\
\text { of students who started using } \\
\text { alcohol at two time } \\
\text { points } 8^{\text {th }} \text { and } 10^{\text {th }} \text { grades) }\end{array}$ & $\begin{array}{l}\text { Students in the intervention group who were non- } \\
\text { drinkers at baseline showed a moderate effect on } \\
\text { preventing alcohol use by the start of the tenth grade } \\
\text { (log } 0 \mathrm{R} 0.58, \mathrm{p}<0.01) \text {. In particular, the } \\
\text { intervention reduced the likelihood of initiating } \\
\text { alcohol use among girls who were non-drinkers at } \\
\text { baseline }(0 \mathrm{R} 0.76, \mathrm{p}=0.02) \text { but not for boys ( } \mathrm{OR} \\
1.23, \mathrm{p}=0.13 \text { ). }\end{array}$ \\
\hline
\end{tabular}

CCT, controlled clinical trial; CI, confidence interval; $\mathrm{C}-\mathrm{RCT}$, cluster randomized controlled trial; $\mathrm{OR}$, odds ratio

\section{Intervention effects}

Analysis of the selected papers revealed inconsistent intervention effects among the reviewed studies. However, the interventions tended to have a positive effect on students who were non-drinkers at baseline, with this effect being stronger in girls. We did not find robust evidence that school-based interventions improved attitudes to alcohol use or reduced the frequency/quantity of drinking or intentions to use alcohol. However, one intervention showed increased alcohol refusal self-efficacy.

Karnell et al. ${ }^{25}$ reported that their intervention neither contributed directly to reducing alcohol-related behaviors nor improved alcohol-related variables, including alcohol related self-efficacy. Smith et al. ${ }^{27}$ reported strong intervention effects on past month drinking in girls, and positive effects in both sexes; however, among the subsample of baseline non-drinkers, only girls showed a positive intervention effect ${ }^{27}$. Cupp et al. ${ }^{26}$ reported that the intervention groups showed a greater increase in alcohol refusal self-efficacy compared with the control groups, with this effect being greater in boys than girls. However, no intervention effects were reported for attitudes and intentions to use alcohol and ever using alcohol ${ }^{26}$. Moreover, Cupp et al. ${ }^{26}$ reported high attrition, and noted that students who stayed in the study until the end of the intervention exhibited safer attitudes and behavior than at baseline. These results indicated that the program might have been ineffective for students at higher risk ${ }^{26}$. Finally, Motamedi et al. ${ }^{29}$ reported their intervention reduced the likelihood of initiating alcohol use among girls who were non-drinkers at baseline. 


\section{Quality of studies}

The results of the risk of bias assessments are shown in Figures 2 and 3. The percentages of attrition were $19 \%$ for Karnell et al. ${ }^{25}$, 38\% for Smith et al. ${ }^{27}, 55 \%$ for Cupp et al. ${ }^{26}$, and $10 \%$ for Motamedi et al. ${ }^{28}$.

We found the quality of included studies was poor, especially in terms of random sequence generation and completing outcome data. Information about allocation concealment and blinding of outcome assessment was unclear in the two C-RCTs ${ }^{27,28}$. In addition, the two CCT studies were evaluated as having a serious risk in the overall risk of bias judgment ${ }^{25,26}$. The four selected studies did not share the same study design or the same outcome indicators. Moreover, it was difficult to consider the studies as homogeneous because of insufficient information on study participants and the languages used in questionnaires, as well as minor differences in intervention methods (e.g., peer leader training). Because of the above-mentioned heterogeneity, the results could not be integrated, and a meta-analysis could not be performed.

\section{Discussion}

Results of our review suggested that multi-component interventions using participatory approaches targeted at secondary school students who have not started drinking may be effective for school-based alcohol use prevention in South Africa.

Interventions tended to have a positive effect on students who were non-drinkers at baseline, with this effect being stronger in girls. Motamedi et al. ${ }^{28}$ noted that providing additional leisure options as a measure to prevent substance use in a low resource setting may offer a promising break from the typical limited activities that may bore girls compared with boys (who tend to engage in more fun activities such as sports or hanging out with friends). Interventions that include components focused on leisure activities as a measure to prevent substance use, especially among girls, may fit with the African context.

Programs modified from those developed in other countries may be applicable in Africa. Using modified programs may also contribute to saving costs and efforts in developing intervention programs, provided cultural differences are considered. HealthWise was developed by combining three separate interventions that had been implemented independently in the US ${ }^{29}$. One of these three interventions included elements of a life skills training program ${ }^{30}$, the second was an evidence-based leisure education intervention ${ }^{31}$, and the third used an integrated approach drawn from various sexuality curricula ${ }^{29}$. Wegner et al. ${ }^{29}$ noted that combining the three interventions into one package allowed an integrated approach to broader based social skills (e.g., managing risk), and addressed issues such as shortage of teaching time, language problems, and lack of different resources. For example, to address the shortage of teaching time, the program was divided into grades 8 and 9 to secure sufficient time. In terms of language, the program used familiar terms drawn from students' own language and words usually used in South Africa. To address the lack of physical and financial resources, the program provided two youth development specialists and support for educators. As illustrated in the selected studies, considering the lack of resources and cultural limitations is essential when adapting existing programs for African countries.

The original Our times, Our Choices program reported positive effects in several outcomes: 1) reducing alcohol use, 2) reducing the tendency to use alcohol, 3) reducing the combination of cigarette and alcohol use, 4) changing the functional meanings of alcohol use, 5) reducing peer norms and peer influence to use, 6) introducing skills to resist peer influences, and 7) increasing parent-child communication about the consequences of drinking ${ }^{32}$. However, one study that involved the Our times, Our Choices program reported no significant direct intervention effects on any of the alcohol-related outcomes and mediating alcohol-related variables ${ }^{25}$. The other study reported there were no intervention effects with regard to attitudes and intention to use alcohol, although the intervention groups showed a greater increase in the ability to refuse alcohol and alcohol refusal self-efficacy than the control groups ${ }^{26}$. Moreover, it was reported that alcohol-related behavioral outcomes also showed no significant intervention effects for ever using alcohol ${ }^{26}$. In the original program, some activities involved parents as well as students and teachers ${ }^{32}$. This difference may explain why the modified program in South Africa was less effectiveness compared with the original program.

Previous systematic reviews reported that multi-component interventions were effective, although there was little evidence that interventions with multiple components were more effective than interactive interventions with single components ${ }^{15,16,19}$. Moreover, a systematic 
review by Mark et al. ${ }^{33}$ reported that the most effective prevention programs to reduce marijuana and alcohol use among adolescents aged 10-15 years in the long-term were comprehensive programs that included anti-drug information combined with refusal skills, self-management skills, and social-skills training. An earlier study reported that important components of effective drug abuse prevention curricula were social resistance skills training, normative education, broader-based skills training, and comprehensive health education ${ }^{34}$. Our review found similar results to that study. A systematic review by Fisher et al. ${ }^{35}$ reported there was a strong relationship between risk for alcohol use and HIV infection in Africa. This suggested that providing preventive education targeting reducing alcohol use and HIV infection, and decreaing risky sexual behavior may be effective in the African context.

In terms of targeting, methodology, and education content, Sussman ${ }^{36}$ argued that to pursue prosocial goals, children aged 12-15 years have to learn about consequences of drug use, refusal assertion, decision making, counteracting social influences to use drugs, and life skills through means such as classroom discussion and peer group interaction. The effectiveness of participatory methods such as peer and interactive education has been proven in previous meta-analyses ${ }^{15,37}$. A systematic review by Cuijpers ${ }^{38}$ also reported peer education methods were effective. Cuijpers ${ }^{38}$ concluded that adding life skills training to such programs may strengthen the effects. Furthermore, Dusenbury et al. ${ }^{34}$ reported that interactive teaching techniques are an important component of effective drug abuse prevention curricula. Our review found similar results to these studies. These findings suggested that alcohol use prevention education should involve participatory methods and focus on developing students' social-emotional skills as well as education about risk behaviors. Moreover, these prevention activities should be incorporated into existing curricula as part of official health education. The importance of integrating this information into school curricula has been highlighted in previous reviews ${ }^{34,39}$.

In a recent systematic review, Strøm et al. ${ }^{40}$ reported that school-based programs had potential to reduce alcohol use among adolescents. However, that review indicated that most drug prevention programs have no effect ${ }^{40}$. Similarly, we could not find robust evidence that school-based interventions in Africa improved students' attitudes, and reduced the frequency/quantity of drinking and intentions to use alcohol. Nevertheless, Strøm et al. ${ }^{40}$ and other reviews argued that schoolbased interventions were most effective for preventing and reducing alcohol use among adolescents when delivered as primary prevention programs to youth who had not yet started drinking ${ }^{39,41}$. One intervention in our study also showed positive effects on non-drinkers at baseline. This finding suggested that prevention programs may need to be implemented before seventh grade, and should address the risks associated with early drinking ${ }^{32,42}$. Gottfredson et al. ${ }^{43}$ argued that programs targeting junior high school students were marginally more effective than those targeting adolescents in elementary or high schools. The above evidence emphasized the importance of appropriate timing of interventions. Furthermore, tobacco and other drug abuse prevention programs may need to be tailored to specific human developmental stages ${ }^{36}$. For children, interventions to prevent alcohol use should be provided before initiation of drinking.

Heterogeneity among the reviewed studies was attributed study participants, languages used in questionnaires, and evaluation of the effects of peer leader training. First, participants in all interventions were students in grades 8 or 9 . However, some papers lacked sufficient information about participants, such as race and the sex ratio. Therefore, it is uncertain whether possible differences in participnts influenced the intervention results. Second, some studies noted that a local language was used for the questionnaire, whereas others did not clearly state the language used. This might have created some differences in intervention results. Nevertheless, it was difficult to evaluate these differences because of the non-uniformity of outcome indicators among the studies. Third, all studies applied modified programs originally developed in the US. However, some studies included peer leader training, whereas others did not; this difference might also have affected the results. The lack of evaluation of the effects of training in the reviewed studies meant that we could not examine the influence of training. This suggests that papers reporting on interventions should include basic information necessary to enable the evaluation of heterogeneity among the studies.

\section{Limitations}

Few of the retrieved papers were selected for systematic review, and we could not conduct a meta-analysis because of the heterogeneity among studies. In addi- 
tion, selected papers only reported interventions in an upper middle-income country. Africa has diverse religions, races, and school systems. Therefore, this review may not be representative of school-based alcohol use prevention activities in the whole of Africa.

\section{Conclusion}

The intervention effects were inconsistent among the selected studies. However, it is noteworthy that the interventions had positive effects on students who were non-drinkers at baseline, especially girls. This review suggests that school-based preventive interventions for alcohol use that incorporate multi-component activities and are based on participatory methods may be effective for secondary school students in Africa who have not yet started drinking. Such interventions should be incorporated into existing school-based health promotion activities. Using programs modified from those developed in other countries is recommended to minimize costs and efforts in developing intervention programs.

\section{Contribution}

S.T., K.M., T. Akiyama, Y.M., A.N. J.K. and M.J contributed to design the study. S.T. wrote the initial draft of the manuscript. S.T. and K.M. performed the analysis and interpreted the analyzed data. K.M. and T. Asakura assisted in the preparation of the manuscript. N.S., A.I. and other authors contributed to critical interpretation to the manuscript. All authors approved the final version of the manuscript, and agree to be accountable for all aspects of the work in ensuring that questions related to the accuracy or integrity of any part of the work are appropriately investigated and resolved.

\section{Acknowledgements}

This work was supported by the Grant from National Center for Global Health and Medicine (27A-1, 30A-4) and by Ministry of Health, Labour and Welfare of the Government of Japan (2016-2017)

\section{Conflict of interest disclosure}

The authors declare no conflicts of interest associated with this manuscript.

\section{References}

1. World Health Organization. Global status report on non-communicable diseases 2014. 2014Online Available at: http://apps.who.int/iris/bitstre am/10665/148114/1/9789241564854_eng.pdf?ua=1 (last accessed 12 July 2018)
2. World health organization, Global Status report on alcohol and health 2014. 2014Online Available at: http://apps.who.int/iris/bitstre am/10665/112736/1/9789240692763_eng.pdf (last accessed 12 July 2018)

3. Ferreira-Borges C, Rehm J, Dias S, Babor T, Parry $\mathrm{CDH}$. The impact of alcohol consumption on African people in 2012: an analysis of burden of disease. Trop Med Int Health. 2016; 21(1): 52-60 doi: 10.1111/ tmi.12618.

4. Grant BF, Dawson DA. Age at onset of alcohol use and its association with DSM-IV alcohol abuse and dependence: results from the National Longitudinal Alcohol Epidemiologic Survey. J Subst Abuse. 1997; 9: 103-110

5. Grant BF. Age at smoking onset and its association with alcohol consumption and DSM-IV alcohol abuse and dependence: results from the National Longitudinal Alcohol Epidemiologic Survey. J Subst Abuse. 1998; 10(1): 59-73

6. Kraus L, Bloomfield K, Augustin R, Reese A. Prevalence of alcohol use and the association between onset of use and alcohol-related problems in a general population sample in Germany. Addiction. 2000; 95(9): 13891401

7. DeWit DJ, Adlaf EM, Offord DR, Ogborne AC. Age at first alcohol use: a risk factor for the development of alcohol disorders. Am J Psychiatry. 2000; 157(5): 745-750 8. Sartor CE, Lynskey MT, Heath AC, Jacob T, True W. The role of childhood risk factors in initiation of alcohol use and progression to alcohol dependence. Addiction. 2007; 102(2): 216-225

9. Hingson RW, Heeren T, Zakocs R. Age of drinking onset and involvement in physical fights after drinking. Pediatrics. 2001; 108(4): 872-877

10. Hingson RW, Edwards EM, Heeren T, Rosenbloom D. Age of drinking onset and injuries, motor vehicle crashes, and physical fights after drinking and when not drinking. Alcohol Clin Exp Res. 2009; 33(5): 783-790 doi:10.1111/j.1530-0277.2009.00896.x.

11. Hingson RW, Heeren T, Jamanka A, Howland J. Age of drinking onset and unintentional injury involvement after drinking. JAMA. 2000; 284(12): 1527-1533

12. Cherpitel CJ, Martin G, Macdonald S, Brubacher JR, Stenstrom R. Alcohol and drug use as predictors of intentional injuries in wwo emergency departments in British Columbia. Am J Addict. 2013; 22(2): 87-92 doi: 10.1111/j.1521-0391.2013.00316.x.

13. World Health Organization, Global action plan for the prevention and control of NCDs 2013-2020. 2013 
Online Available at: http://apps.who.int/iris/bitstre am/10665/94384/1/9789241506236_eng.pdf?ua=1 (last accessed 12 July 2018)

14. Every Woman Every child, The Global Strategy for Women's, Children's and Adolescents' Health (20162030). 2015 Online Available at : http://www.who.int/ pmnch/media/events/2015/gs_2016_30.pdf?ua=1 (last accessed 12 July 2018)

15. Tobler NS, Roona MR, Ochshorn P, Marshall DG, Streke AV, Stackpole KM. School-based adolescent drug prevention programs: 1998 meta-analysis. J Prim Prev. 2000; 20(4): 275-336

16. Foxcroft DR, Tsertsvadze A. Universal schoolbased prevention programs for alcohol misuse in young people. Cochrane Database Syst Rev. 2011; (5) doi:10.1002/14651858.CD009113.

17.Champion KE, Newton NC, Barrett EL, Teesson M. A systematic review of school-based alcohol and other drug prevention programs facilitated by computers or the internet. Drug Alcohol Rev. 2013; 32(2): 115-123 doi: 10.1111/j.1465-3362.2012.00517.x.

18. Agabio R, Trincas G, Floris F, Mura G, Sancassiani F, Angermeyer MC. A Systematic review of school-based alcohol and other drug prevention programs. Clin Pract Epidemiol Ment Health. 2015; 11(Suppl 1: M6): 102-112 doi: 10.2174/1745017901511010102. eCollection 2015. 19. Das JK, Salam RA, Arshad A, Finkelstein Y, Bhutta ZA. Interventions for adolescent substance abuse: an overview of systematic reviews. $J$ Adolesc Health. 2016; 59(4 Suppl): S61-S75 doi: 10.1016/j.jadohealth.2016.06.021.

20. Higgins JPT, Green S (editors). Cochrane handobook for systematic reviews of interventions. Chichester (UK): John Wiley \& Sons, 2008

21. Moher D, Liberati A, Tetzlaff J, Altman DG, PRISMA Group. Preferred reporting items for systematic reviews and meta-analyses: the PRISMA statement. BMJ. 2009; 339:b2535 doi: 10.1136/bmj.b2535 PMID: 19622551

22. Higgins JPT, Altoman DG, Gøtzsche PC, The Cochrane Collaboration's tool for assessing risk of bias in randomised trials. BMJ. 2011; 343:d5928 doi: 10.1136/bmj.d5928

23. Higgins JPT, Altoman DG, Sterne JAC (editors). Chapter 8: Assessing risk of bias in included studies, Part 2: General methods for Cochrane reviews. In Cochrane handbook for systematic reviews of interventions Version 5.1.0 updated March 2011, The Cochrane Collaboration.2011; Online Available at: http://handbook-5-1. cochrane.org/ (last accessed 12 July 2018)

24. Sterne JAC, Hernán MA, Reeves BCR, ROBINS-I: a tool for assessing risk of bias in non-randomised studies of interventions. BMJ. 2016; 355:i4919 doi: 10.1136/bmj.i4919

25. Karnell AP, Cupp PK, Zimmerman RS, Feist-Price S, Bennie T. Efficacy of an American alcohol and HIV prevention curriculum adapted for use in South Africa: results of a pilot study in five township schools. AIDS Educ Prev. 2006; 18(4): 295-310

26.Cupp PK, Zimmerman RS, Bhana A, Feist-Price S, Dekhtyar O, Karnell A, et al. Combining and adapting American school-based alcohol and HIV prevention programmes in South Africa: the HAPS project. Vulnerable Child Youth Stud. 2008; 3(2): 134-142 doi: 10.1080/17450120701867553

27.Smith EA, Palen LA, Caldwell LL, Flisher AJ, Graham JW, Mathews C. et al. Substance use and sexual risk prevention in Cape Town, South Africa: an evaluation of the HealthWise program. Prev Sci. 2008; 9(4): 311 321 doi: 10.1007/s11121-008-0103-z

28. Motamedi M, Caldwell L, Wegner L, Smith E, Jones D. Girls just want to know where to have fun: preventing substance use initiation in an under-resourced community in South Africa through Health Wise. Prev Sci. 2016; 17(6): 700-709 doi: 10.1007/s11121-016-0654-3

29. Wegner L, Fisher AJ, Caldwell LL, Vergnani T, Smith EA, Healthwise South Africa: cultural adaptation of a school-based risk prevention programme. Health Educ Res. 2008; 23(6):1085-96.

30. Botvin GJ, Kantor LW. Preventing alcohol and tobacco use through life skills training. Alcohol Res Health. 2000; 24: 250-7.

31. Caldwell LL. TimeWise: Taking Charge of Leisure Time Curriculum for Middle School

Students. Scotts Valley, CA: ETR Associates, 2004.

32. Perry CL, Williams CL, Veblen-Mortenson S, Toomey TL, Komro KA, Anstine PS. Project Northland: outcomes of a communitywide alcohol use prevention program during early adolescence. Am J Public Health. 1996; 86(7): 956-965.

33. Lemstra M, Bennett N, Nannapaneni U, Neudorf C, Warren L, Kershaw T, et al. A systematic review of school-based marijuana and alcohol prevention programs targeting adolescents aged 10-15. Addict Res Theory. 2010; 18(1): 84-96 https://doi. org/10.3109/16066350802673224

34. Dusenbury L, Falco M. Eleven components of effective drug abuse prevention curricula. J Sch Health. 1995; 65(10): 420-425

35. Fisher JC, Bang H, Kapiga SH. The association between HIV infection and alcohol use: a systematic review and meta-analysis of African studies. 
Sex Transm Dis. 2007; 34(11): 856-863 doi: 10.1097/ OLQ.0b013e318067b4fd

36. Sussman S. A lifespan developmental-stage approach to tobacco and other drug abuse prevention. ISRN Addict. 2013; 2013: 745783 doi: 10.1155/2013/745783

37. Tobler NS, Stratton HH. Effectiveness of schoolbased drug prevention programs: a meta-analysis of the research. J Prim Prev. 1997; 18(1): 71-128

38. Cuijpers P. Effective ingredients of school-based drug prevention programs. A systematic review. Addict Behav. 2002; 27(6): 1009-1023

39. Stigler MH, Neusel E, Perry CL. School-based programs to prevent and reduce alcohol use among youth. Alcohol Res Health. 2011; 34(2): 157-162
40. Strøm HK, Adolfsen F, Fossum S, Kaiser S, Martinussen M. Effectiveness of school-based preventive interventions on adolescent alcohol use: a meta-analysis of randomized controlled trials. Subst Abuse Treat Prev Policy. 2014; 9: 48 doi: 10.1186/1747-597X-9-48 41. Miller PM, Smith GT, Goldman MS. Emergence of alcohol expectancies in childhood: a possible critical period. J Stud Alcohol. 1990; 51(4): 343-349

42. Stueve A, O'Donnell LN. Early alcohol initiation and subsequent sexual and alcohol risk behaviors among urban youths. Am J Public Health. 2005; 95(5): 887-893 doi: 10.2105/AJPH.2003.026567

43. Gottfredson DC, Wilson DB. Characteristics of effective school-based substance abuse prevention. Prev Sci. 2003; 4(1): 27-38 